\title{
Safety Helmet Implementation with Centralized Information System on Remote Monitoring Applications
}

\author{
Alvinas Deva Sih Illahi ${ }^{1}$, Anatasya Bella ${ }^{2}$, Sugondo Hadiyoso ${ }^{3}$, Suci Aulia ${ }^{4}$ \\ D3 Teknik Telekomunikasi, Telkom Applied Science School,Telkom University \\ Jl. Telekomunikasi Terusan Buah Batu, Bandung, Indonesia \\ alvinas.deva@gmail.com ${ }^{1}$ \\ abanatasya@gmail.com² \\ sugondo@telkomuniversity.ac.id ${ }^{3}$ \\ suciaulia@telkomuniversity.ac.id ${ }^{4}$
}

\begin{abstract}
Personal Protective Equipment (PPE) is standard equipment that required to ensure safety of workers. PPE equipment that used during work such as: Safety helmet, safety glass, and ear plug. PPE that being used by workers doesn't informative yet, only serve as personal protective so evacuation prevention still looks difficult to do prior accident happened. In this research, Safety Helmet Project has been implemented with pulse sensor, temperature sensor, carbon monoxide gas sensor, and transmission media which able transmitting data to control and monitoring center. The system also supports multiuser monitoring applications that can be accessed simultaneously through the internet network. Based on test results, the comparison of measurement gap with standard tool has been obtained as temperature sensor is $0,07 \%$, heart sensor is $\pm 4 \%$. Accuracy level for temperature sensor and heart rate are $99,67 \%$ and $95,45 \%$ by various condition of test. Another test is delay of the transmitting sensor data to the website around \pm 10 seconds and controlling around \pm 5 seconds.
\end{abstract}

Keywords: PPE, Safety Helmet, Monitoring, Multiuser, Website.

\section{Introduction}

Occupational Health and Safety (OHS) is one aspect of labor protection and also protecting the company's assets. This is reflected in the Law No. 1 of 1970 on occupational safety. Based on Ministerial Regulation No. PER.08/MEN/VII/2010, every worker must wear Personal Protective Equipment (PPE). PPE is an equipment used to protect workers against occupational health or safety risks such as safety helmets and hard hats, gloves, eye protection, high visibility clothing, safety footwear [1]. Every employer is also required to provide PPE for workers / laborers with specifications in accordance with applicable standards. It aims to reduce the risk of casualty casualties in the workplace, even some studies [2-5] have addressed policy analysis in public health in particular. The PPE used should take into account the potential hazards and risks of the workplace so that it will effectively protect workers. The types of work required to use PPE include: construction, mining, working with chemicals, laboratory work, electrical work, factories or work related to electromagnetic radiation.

One of the personal protective equipment for construction, mine, or electrical work is a helmet that generally serves as a protector of [6] falling objects, withstand blows, retains water and fire. Protective helmets commonly used by workers are still protecting the individual personally but have not been able to send the workers condition information to others so that evacuation or early rescue action is difficult to do in the event of an accident so that a smart monitoring system is needed for workers who can reduce the number of accidents and work protection [7-8]. This integrated system should be able to provide an overview of workers' health and workplace environment. This integrated system should be able to provide an overview of workers' health and workplace environment. The system is also capable of reading the parameters that are considered necessary then sending the information to be monitored centrally. The centralized information system is expected to provide ease of access at a much lower cost [9] for interested parties. 
Some researchers have implemented a safety monitoring system to improve comfort, safety and preventive measures before an accident occurs. A wireless monitoring system on self-employed people [10-11] devices can send alarms to the monitoring center during emergency situations just by pressing a button. However, this system can not measure the vital parameters of the surrounding environment. A study that provides an overview of the importance of a wireless body area network device with an embedded system to ensure the safety of construction workers has also been done [12-13]. The results of this study can be used as the basis for the development of devices to monitor the conditions of workers. Other research on the realization of the device monitoring the vital parameters of the body on workers has also been done on [1415]. However, the monitoring system is still local, not yet connected to the global internet network and tends to be point to point. A system capable of central monitoring and multiple access [16] is required for a number of workers and the ease of viewing data online and realtime over the internet. Several studies that have successfully presented a monitoring system based on both smart phones and desktop applications [17-18] aim to facilitate access to remote monitoring.

In this research PPE has been made in the form of helmets equipped with sensors that can determine workers health condition and environment. Built-in sensors have functions, pulse sensors are used to calculate the worker's heartbeat, the temperature sensor used to detect the working environment temperature and the gas sensor can detect the presence of harmful gases in the working environment. Furthermore, the three parameters are transmitted by the transmission module to the Internet network so that it can be accessed online, realtime and simultaneously through the website page. This system not only works point to point, but also can be used by more than one worker to be monitored simultaneously. An authorized person can then conduct a monitoring worker to find out the conditions and conditions of the worker either under normal or emergency conditions. With this system is expected to conduct the process of monitoring workers, take precautions and facilitate the evacuation when an accident occurs.

\section{Research Method}

Implementation of information systems on safety helmets consists of two main sub-systems are hardware and software. Hardware has a major function for the acquisition of heart rate, environmental temperature, carbon monoxide gas as well as responsible for data transmission. The acquisition function is performed by pulse sensor, DS18B20 sensor and MQ-7 gas sensor. An arduino microcontroller will read sensor data, perform multiplexing functions and synchronize digital data transmission with ESP-8266 WiFi module. Software is a website application that works to process digital data so it can be represented in the form of numerical and graphics. The application also has a function to sort the user identity data and sensor data.

This system will provide alarm alerts via buzzer and send notifications when the hazard is indicated. The threshold to determine the condition is carbon monoxide value is $\geq 25 \mathrm{ppm}$, environmental temperature magnitude $\geq 30^{\circ} \mathrm{C}$, the number of heartbeats $\geq 190 \mathrm{bpm}$. The carbon monoxide threshold value based on OSHA (Occupational Safety and Healt Administration) is $25 \mathrm{ppm}$. Pulse sensors are placed on the ear, where the maximum limit approach of the human heartbeat can be determined by calculation:

$$
\text { Bpm max }=220-\text { Age }
$$

If we take an average age sample of workers 30 years then the heart rate threshold is not more than $190 \mathrm{Bpm}$.

The information system used in this system is based on website application using PHP and MySQL database. Through website pages, authenticated users can monitor the environment temperature, heart pulse, carbon monoxide. The information system can also control the tool by turning on the buzzer to call the worker if necessary. 


\section{System Design}

Design of safety helmet consists of two main parts as described in the previous section, designing the hardware and software design as a monitoring system. The hardware of safety helmet consists of 3 sensors, there are the heartbeat sensor, temperature sensor, and gas sensor. While the software section displays the data on the website sent by WiFi module ESP8266. The whole system overview can be seen in Figure 1 below.

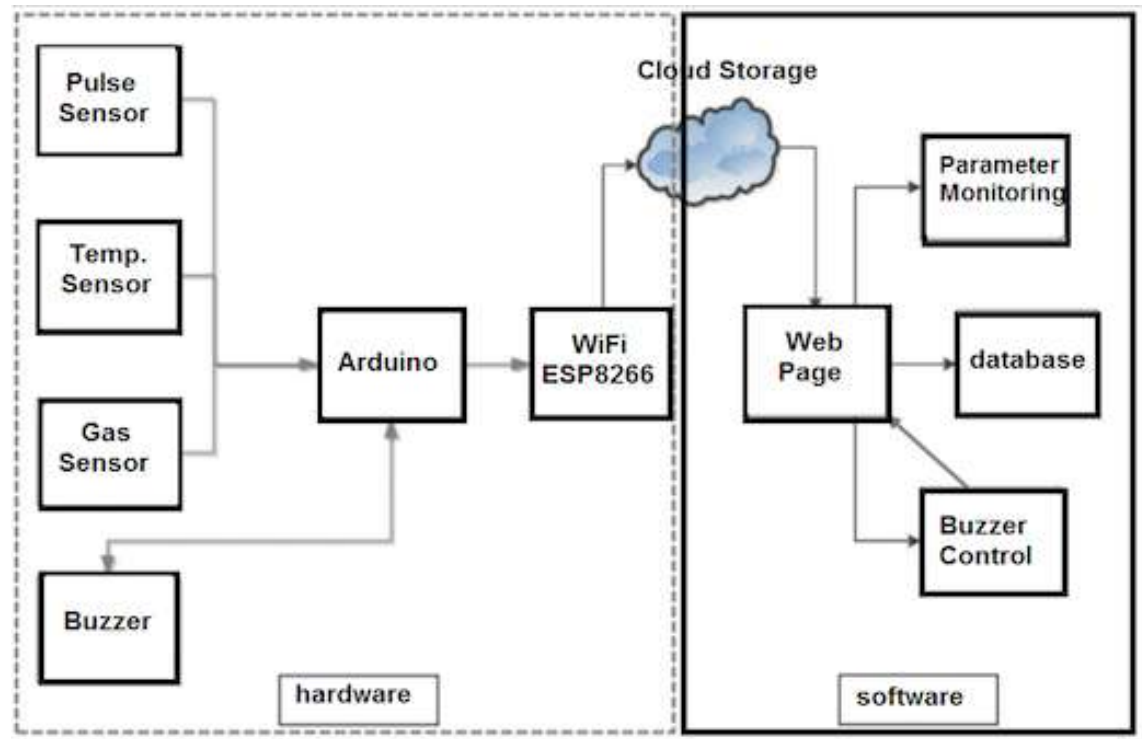

Figure 1. System Design

From Figure 1 above, data obtained from pulse sensor, temperature sensor (DS18B20) and gas sensor (MQ-7) are then processed by Arduino and sent via ESP 8266 connected to the WiFi router. The data is automatically entered into the database and displayed on the website so that the supervisor or admin can monitor through the website. In addition there is a buzzer that will sound when the 3 sensors detect the danger conditions or exceed the threshold at a certain level. Figure 2 shows the circuit of the Arduino Uno, ESP 8266, pulse, temperature sensor (DS18B20), gas sensor (MQ-7), buzzer, and resistor components as hardware of safety helmet.

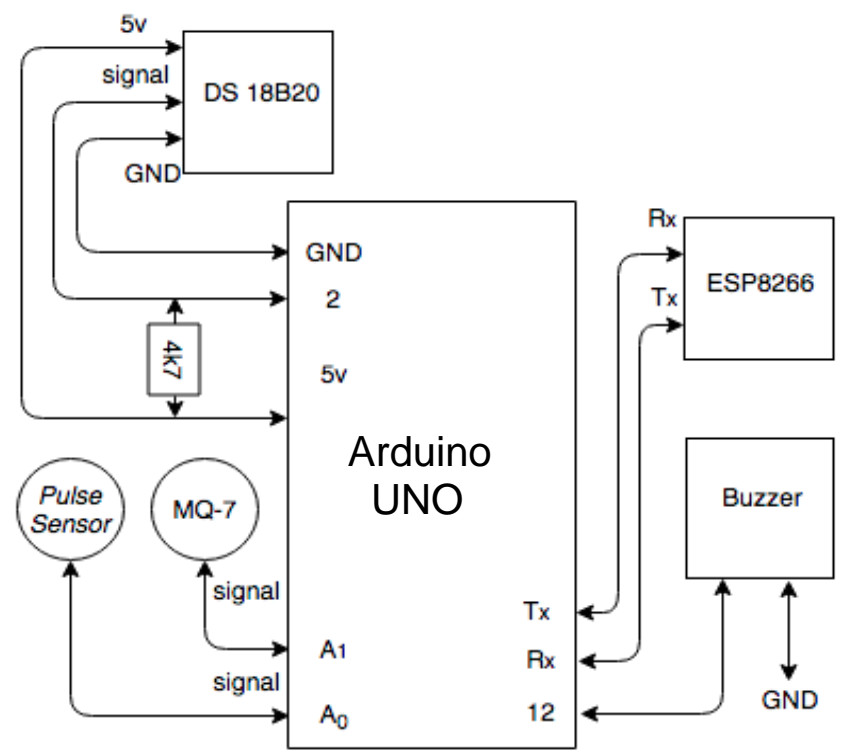

Figure 2. Hardware circuit on safety helmet 
Each sensor has a threshold for activating buzzer that serves as notification, threshold for gas sensor $\geq 25 \mathrm{ppm}$, temperature sensor $\geq 30^{\circ} \mathrm{C}$, and heartbeat sensor $\geq 190 \mathrm{bpm}$. If the sensor reads the data exceeding the threshold, the buzzer will sound and website will display a red sign as an indicator of the worker condition in a state of danger. The flow process can be seen in Figure 3.

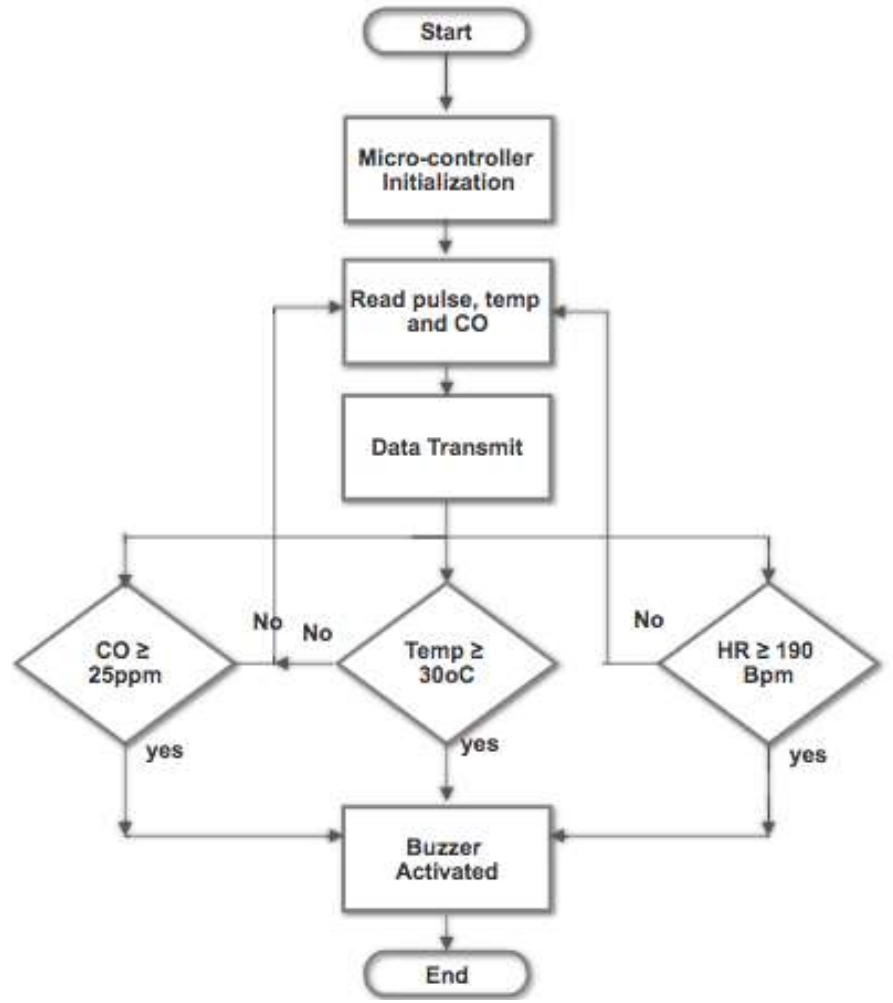

Figure 3. Flow diagram of the safety helmet notification system

\section{Results and Discussion}

In this study, the device (safety helmet) has been implemented that have 3 sensors, there are: MQ-7 sensor (gas CO), sensor DS18B20 (temperature), pulse sensor (heart rate). Figure 4 is a helmet design that has been realized. The readings from each sensor are shown in realtime on the safety helmet by accessing website at http://iotwebserver.id/.
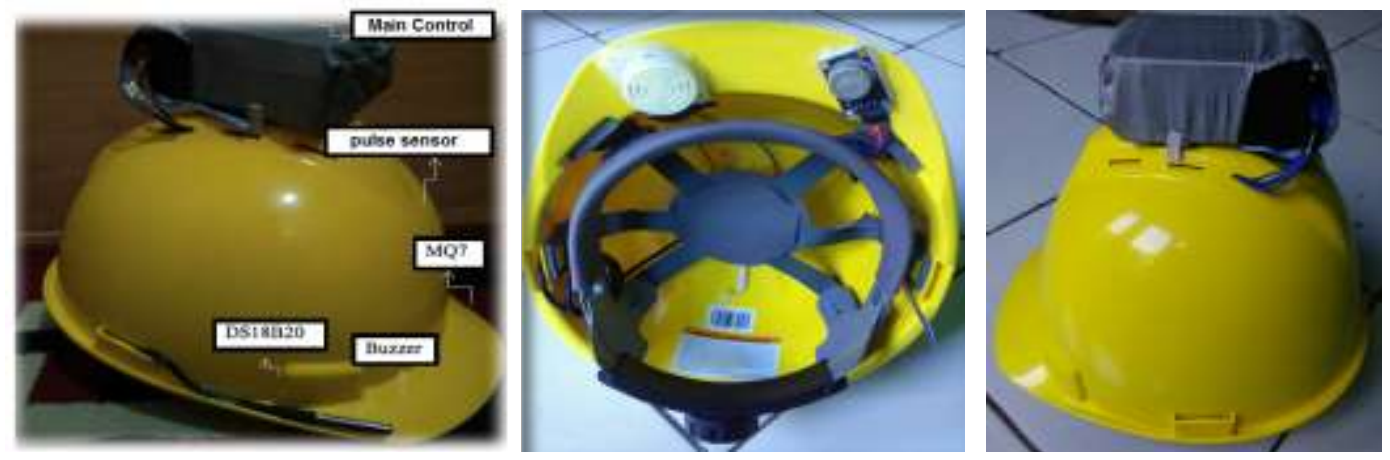

Figure 4. Safety helmet

\subsection{Hardware Testing}

Hardware testing is a test of the functionality of each sensor, by comparing the measurement results that read by the sensor with device or other applications. 


\subsubsection{Temperature Measurement}

As temperature sensor calibration of $\mathrm{DS} 18 \mathrm{~B} 20$, the first step is measurement of room temperature. If the room temperature is at $\geq 30^{\circ} \mathrm{C}$ then the worker's temperature is declared a hazard condition and buzzer will sound. Comparison of temperature measurement results between digital thermometer and DS18B20 sensor can be seen in Figure 5.

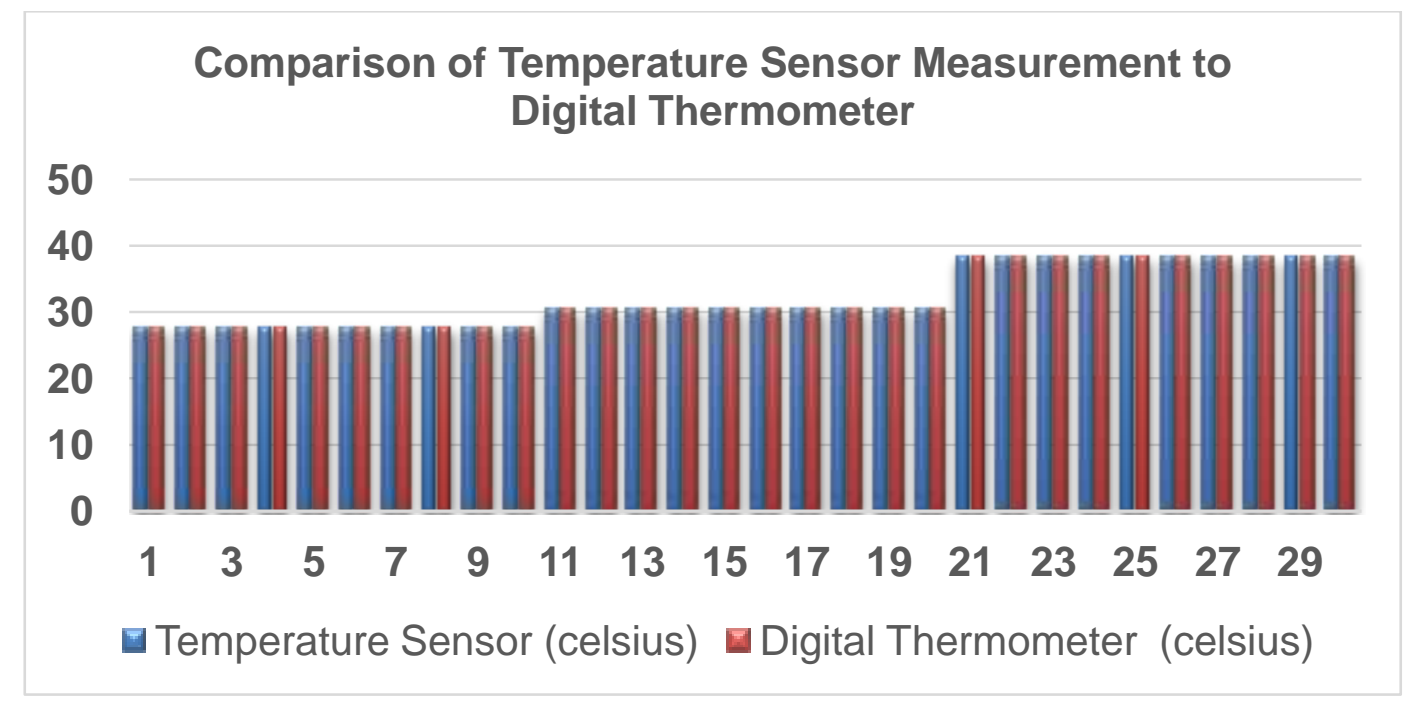

Figure 5. Accuracy testing of DS18B20 temperature sensor

From Figure 5 above shows an average error of $0.077 \%$ with an accuracy of $99.923 \%$, this is influenced by the position of thermometer and sensor placement.

\subsubsection{Carbon Monoxide Gas Measurement}

The threshold of the carbon monoxide gas content in the air is $\geq 25$ parts per million (ppm), and in normal free air reaches a concentration of about $20 \mathrm{ppm}$ [6]. From the results of 30 times the measurement of carbon monoxide gas using the MQ-7 sensor obtained average value of normal carbon monoxide gas condition of $\pm 20.47 \mathrm{ppm}$, vehicle combustion smoke and waste in large scale of $\pm 23.56 \mathrm{ppm}$ as shown in Figure 6 .

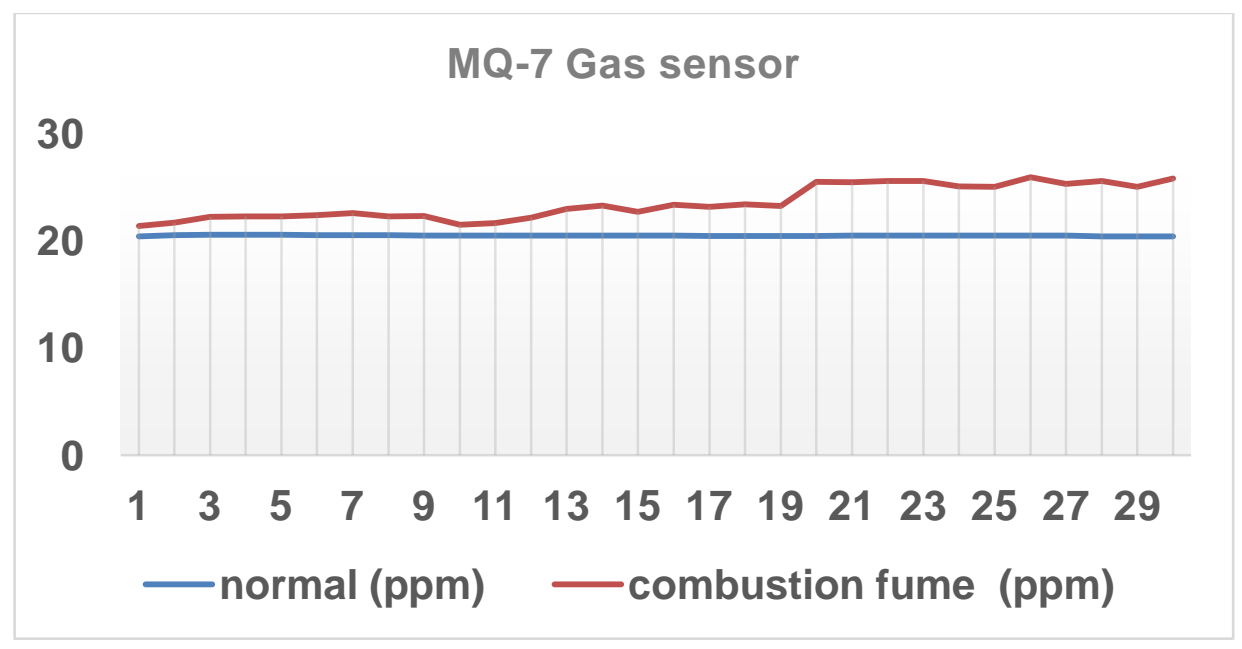

Figure 6. MQ-7 measurement results 


\subsubsection{Heart Rate Measurement}

Heartbeat sensor testing is conducted in two conditions (sample age 22-30 years), 1. when the user in normal condition (60 to $100 \mathrm{Bpm}$ ) and 2. User do heavy activity. From the measurement results, obtained an upper threshold value of $190 \mathrm{Bpm}$ and a lower threshold of $40 \mathrm{Bpm}$. Measurements are made by putting the sensor on the finger, while measuring the application by attaching the fingertips on the camera that there are LED indicators. Real heartbeat measurements were made to construction project workers in the bekonang area, Sukoharjo District, Central Java. From the results of heart rate measurement of normal activity conditions using the application of instant heart rate app and heartbeat sensors obtained results as in Table 1 and Figure 7 follows:

Table 1. Measurement heart rate (normal activity)

\begin{tabular}{|c|c|c|c|}
\hline \multirow[t]{2}{*}{ User } & \multicolumn{2}{|c|}{ Heart rate } & \multirow[t]{2}{*}{ accuracy $(\%)$} \\
\hline & $\begin{array}{l}\text { Application } \\
\text { (Bpm) }\end{array}$ & $\begin{array}{l}\text { Safety helmet } \\
\text { (Bpm) }\end{array}$ & \\
\hline Anggono & 74.6 & 71.8 & 96.24 \\
\hline Heru & 89 & 86.8 & 97 \\
\hline Ratno & 60 & 63.2 & 94.4 \\
\hline Suparno & 59 & 62.8 & 93.2 \\
\hline Suwardi & 66 & 69.4 & 94.4 \\
\hline Ratman & 69 & 73 & 93.8 \\
\hline & Ave. & & 94,79 \\
\hline
\end{tabular}

\section{Comparsion Heart Sensor to Instant Heart Rate Aplication (Normal Condition)}

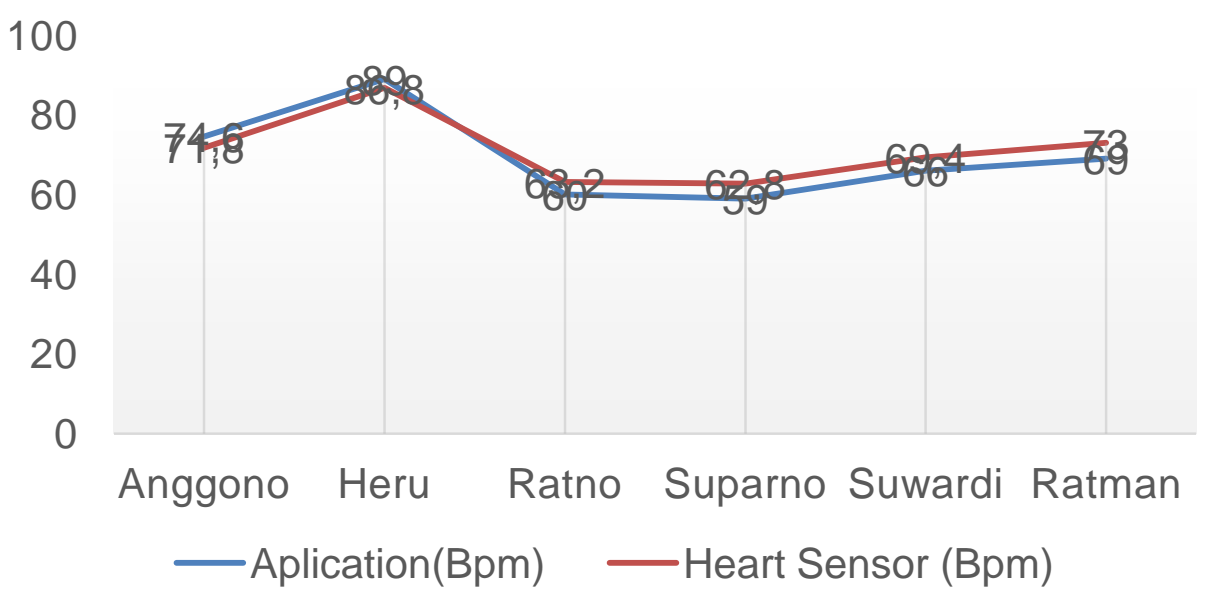

Figure 7. Heart rate sensor measurement of normal activity conditions

From Table 1 the accuracy of heartbeat sensor is $94,79 \%$, average error of $3 \%$ with application in android. Many factors affect the amount of bpm (beat per minute) of them, temperature, age and activity performed. While the level of accuracy obtained during heavy activity conditions of $96.8 \%$ and an average error of $3.36 \%$ with applications in android showed higher values. 


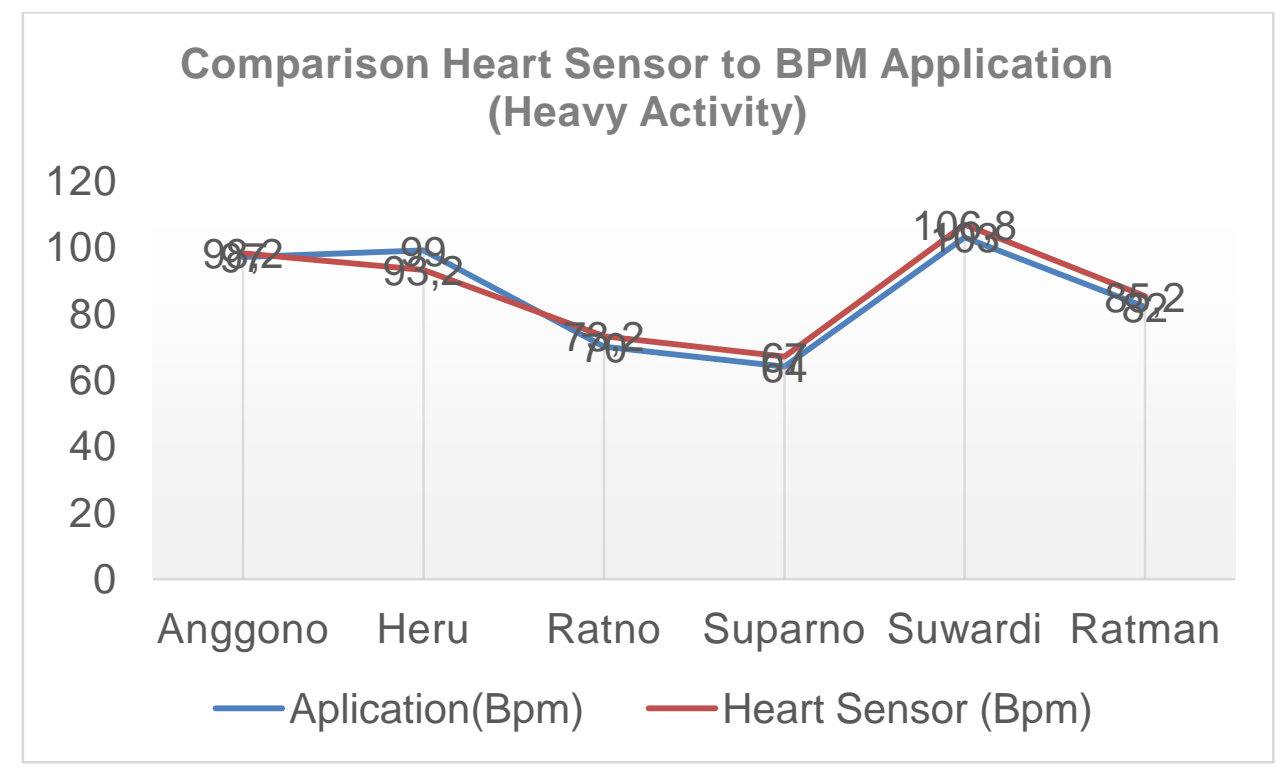

Figure 8. Heart rate sensor measurement of heavy activity conditions

\subsection{Testing Reliability of Data Transmission}

Safety helmet system is applied to the building environment or underground lane so that required simulation testing on the condition of the environment. In this test performed simulation of performance measurement system in sending data from helmet user to access point which connected with internet network. Simulation of measurement is done on the building with condition there is barrier (between user with access point) in the form of wall. So it will be known the reliability of the system in sending data to the central information system.

Information Systems as a remote monitoring application is a website application that is stored on a VPS Digital Ocean server and can be accessed via http: // iotwebserver / helmmonitoring address. As a preliminary window or "home screen", which is displayed on the website in the form of a brief explanation of the safety helmets shown in Figure 9.

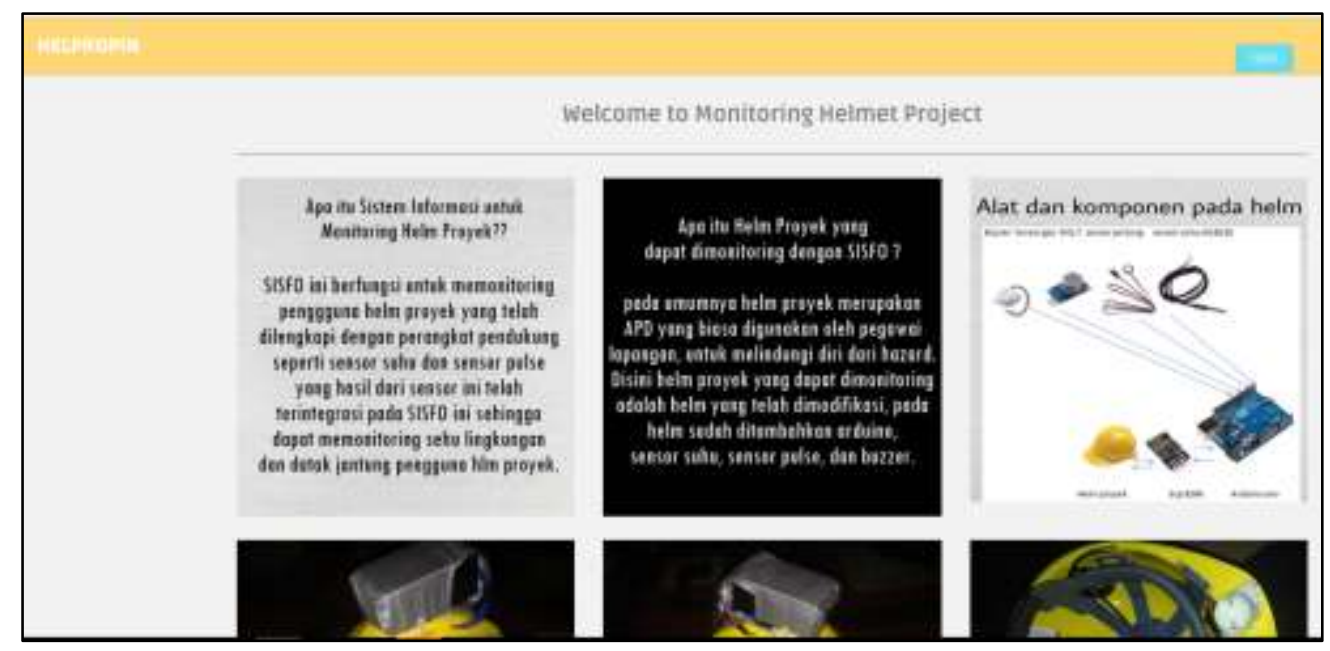

Figure 9. Main page of information system for monitoring safety helmet

While on the monitoring page consists of user identity of safety helmet and sensor parameter value, i.e. user name, helmet number, ambient temperature, heart rate, gas contents around the environment user and alarm button as shown in Figure 10. 


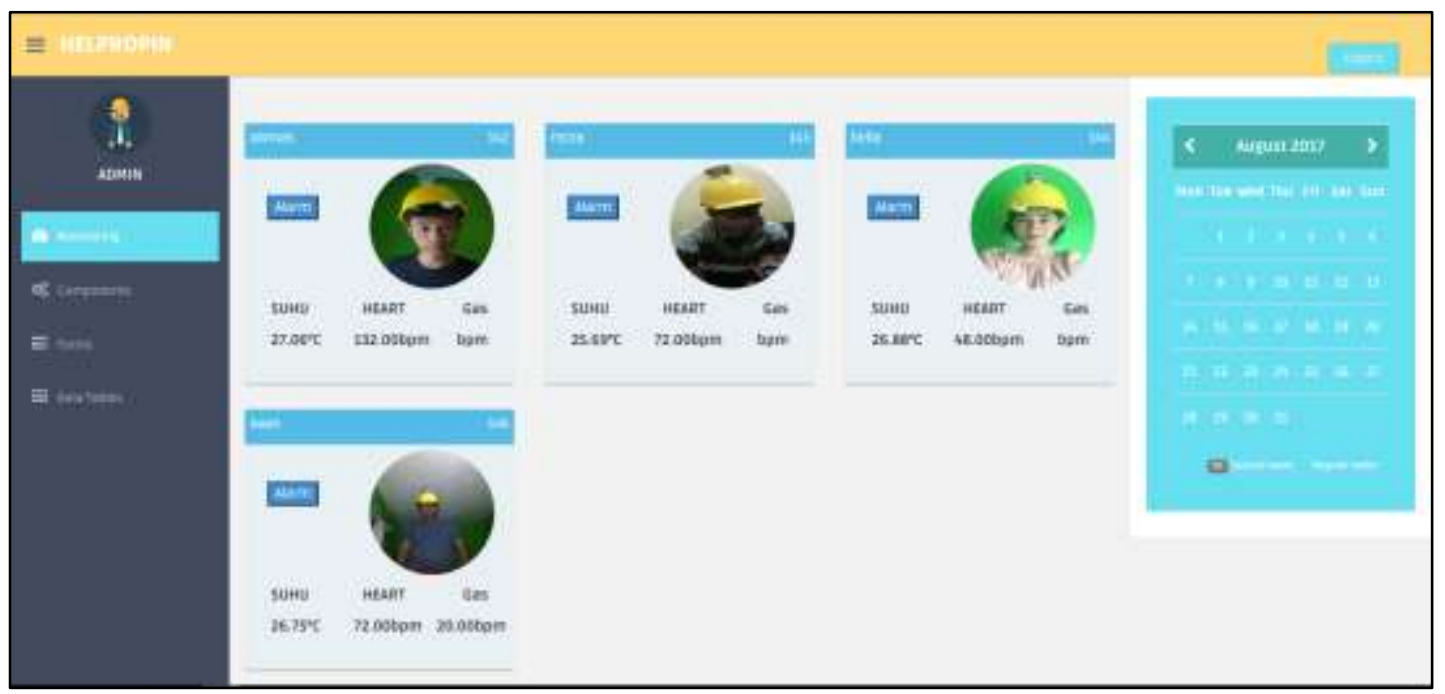

Figure 10. Monitoring page on the safety helmet information system

Testing time of data delivery is also done to calculate the delay during data delivery process take place. From the results of this test, obtained the average delay of sending the sensor data for \pm 10 seconds and delay time to control is \pm 5 seconds. The value of delay depends on internet traffic conditions, distance conditions and barriers in the measurement environment.

Barriers affect the power of send and receive devices that can affect the amount of delay that can cause data not to be sent in remote monitoring applications. Required data storage mechanism (data logger) on the device installed, so that the system can still do data recording when there is no internet connection.

\subsubsection{Webserver Load Server}

This test is performed to determine the ability of the web server in serving access from users. This test is done by using Webserver Stress Tool 8 application, this application works by simulating the user accessing the website page and click on a certain menu. Data retrieval is done by simulating the number of users from $50,60,70,80,100,150$, 250 and 300 users with each user click 10 times on the website page. Figure 11 is a test result performed on the http://iotwebserver/helmmonitoring page.

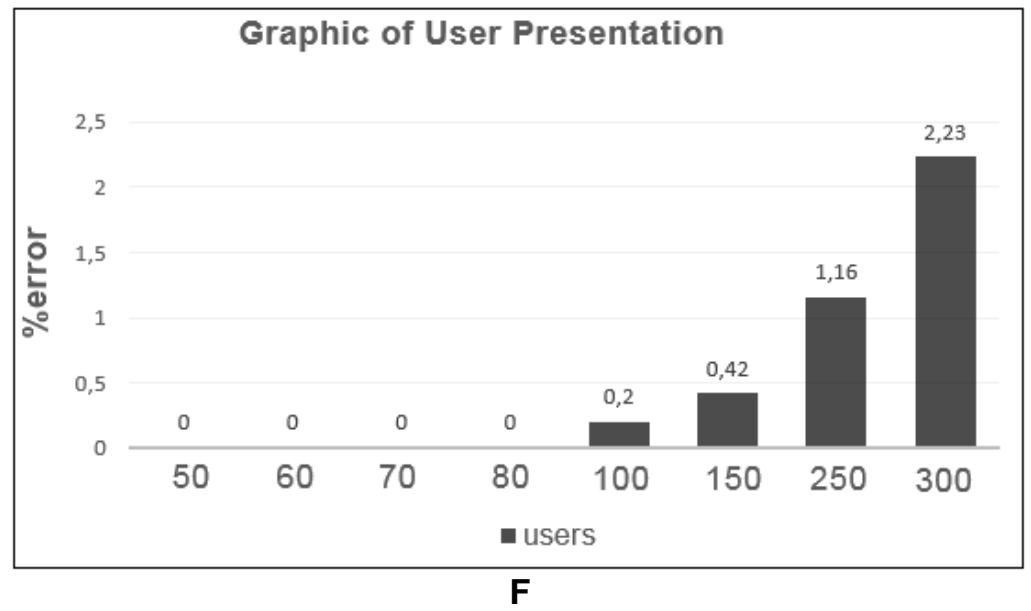

Figure 11. Error percentage on server load testing 
Based on Figure 11, the error occurs when the number of user is 100 that is $0.2 \%$ and increases $2.23 \%$ when the number of user is 300 .

\subsubsection{Storage Capacity Testing}

Testing is done to find out how much data can be stored by server. This website uses VPS Digitalocean with specifications 512MB RAM memory, 1 Vcpu, 20GB SSD, 1TB HDD. Storage capacity for the information system of safety helmet website is $10 \mathrm{~GB}$.

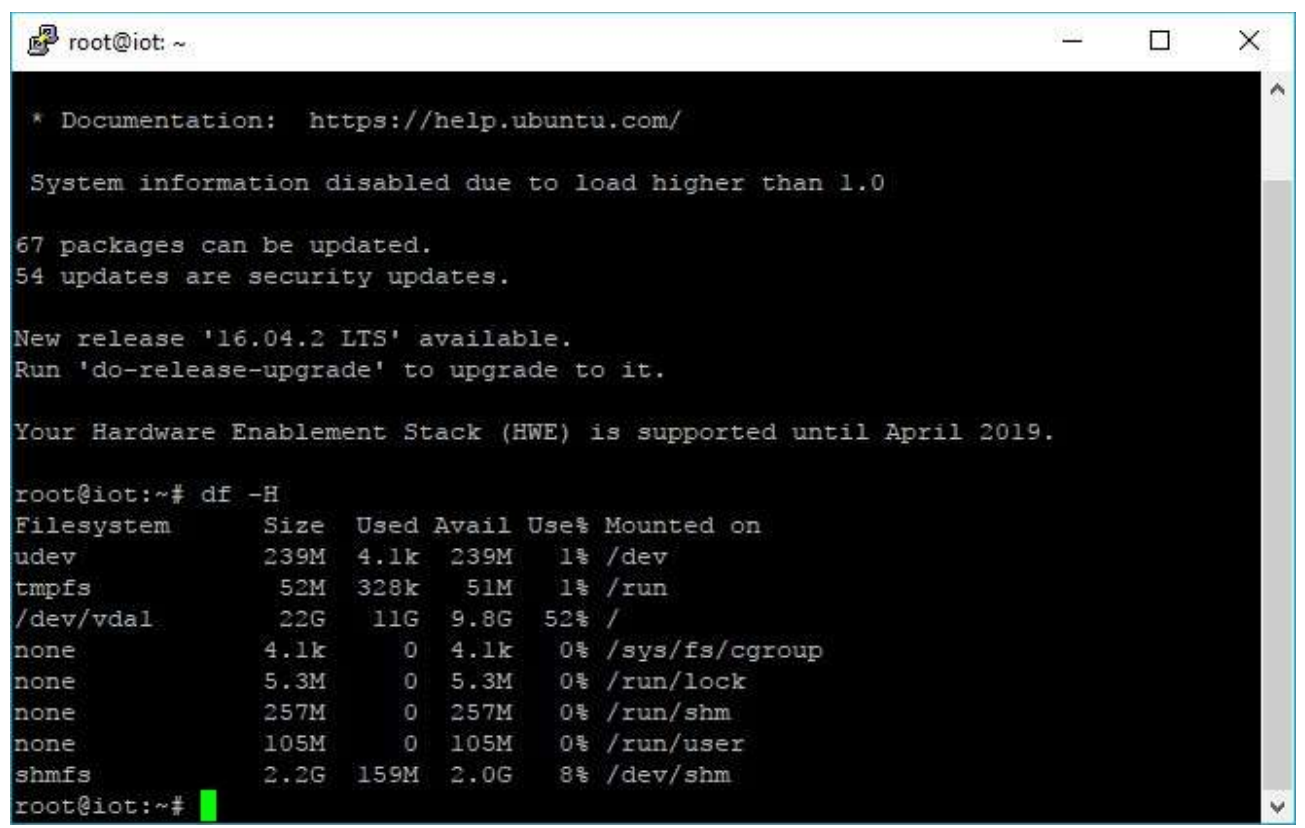

Figure 12. Harddrive capacity of VPS

Based on experiments that have been conducted for 1 hour, there are 360 data entry into the database (average 10 seconds/data) and storage capacity used for 360 data of $40 \mathrm{KiB}$ or $40.96 \mathrm{kB}$. Can be deduced for the storage capacity of $10 \mathrm{~GB}$ of data that can be accommodated $\approx 87.890 .625$ data.

\section{Conclussion}

In this research has successfully implemented a safety helmets and monitor applications. The measured parameters can be monitored through the information system website which can be accessed at http://iotwebserver/helmmonitoring. This information system can be used by officers or administrator who have the authority to view monitoring results that is heart rate, gas, and environmental temperature. From the test results, each sensor (temperature sensor DS18B20 and heart rate sensor) has a accuracy of $99.67 \%$ and $95.45 \%$. Any sensors that detect a state of danger, will provide notification of red writing and for the state of danger on the temperature and gas sensors will automatically buzzer burn. Buzzer indicator is active when carbon monoxide gas $\geq 25 \mathrm{ppm}$, temperature $\geq 30^{\circ} \mathrm{C}$, heart rate $\geq 100 \mathrm{bpm}$ and to call workers. The average delay of sending the sensor data is \pm 10 seconds and controlling \pm 5 seconds. For the next research required data storage mechanism (data logger) on the device installed, so that the recording of data can be used when the system occurs internet connection interruption.

\section{Reference}

[1] Health and Safety Executive (HSE), "Personal protective equipment ( PPE ) at work: A brief guide," Heal. Saf. Exec., pp. 1-6, 2013.

[2] C. Wing, K. Simon, and R. A. Bello-Gomez, "Designing Difference in Difference Studies: Best Practices for Public Health Policy Research,” Annu. Rev. Public Health, vol. 39, no. 1, p. annurev-publhealth-040617-013507, Apr. 2018.

[3] K. Ringen, "Safety and Health in the Construction Industry," Annu. Rev. Public Health, 
vol. 16, no. 1, pp. 165-188, Jan. 1995.

[4] S. C. Moyce and M. Schenker, "Migrant Workers and Their Occupational Health and Safety," Annu. Rev. Public Health, vol. 39, no. 1, p. annurev-publhealth-040617-013714, Apr. 2018.

[5] C. R. C. HASSAN, O.J. BASHA, and W. H. W. HANAFI, "Perception of building consruction workers towards safety, health and environment," J. Eng. Sci. Technol., vol. 2, no. 3, pp. 271-279, 2007.

[6] A. Jacob et al., "Evaluation of Helmet Protection during Impact of Head to Ground and Impact of an Object to Head Using Finite Element Analysis," J. Saf. Eng., vol. 5, no. 1, pp. 8-16, Oct. 2015.

[7] H. K. Koh and K. G. Sebelius, "Promoting Prevention through the Affordable Care Act," N. Engl. J. Med., vol. 363, no. 14, pp. 1296-1299, Sep. 2010.

[8] J. B. Forsyth, T. L. Martin, D. Young-Corbett, and E. Dorsa, "Feasibility of Intelligent Monitoring of Construction Workers for Carbon Monoxide Poisoning," IEEE Trans. Autom. Sci. Eng., vol. 9, no. 3, pp. 505-515, 2012.

[9] P. S. Saputra, I. M. Sukarsa, and I. P. A. Bayupati, "Sistem Informasi Monitoring Perkembangan Anak di Sekolah Taman Kanak - kanak Berbasis Cloud," Lontar Komput. J. Ilm. Teknol. Inf., vol. 8, no. 2, p. 112, 2017.

[10] L. Senyurek, K. Hocaoglu, B. Sezer, and O. Urhan, "Monitoring workers through wearable transceivers for improving work safety," in 2011 IEEE 7th International Symposium on Intelligent Signal Processing, 2011, pp. 1-3.

[11] Y. Zhang, H. Liu, X. Su, P. Jiang, and D. Wei, "on Smart Phone and Browser / Server Structure," J. Healthc. Eng., vol. 6, no. 4, pp. 717-738, 2015.

[12] E. D. Marks and J. Teizer, "Method for testing proximity detection and alert technology for safe construction equipment operation," Constr. Manag. Econ., vol. 31, no. 6, pp. 636-646, Jun. 2013.

[13] P. Acharya, B. Boggess, and K. Zhang, "Assessing Heat Stress and Health among Construction Workers in a Changing Climate: A Review," Int. J. Environ. Res. Public Health, vol. 15, no. 2, p. 247, Feb. 2018.

[14] P. Aqueveque, C. Gutiérrez, F. S. Rodríguez, E. J. Pino, A. S. Morales, and E. P. Wiechmann, "Monitoring Physiological Variables of Mining Workers at High Altitude," IEEE Trans. Ind. Appl., vol. 53, no. 3, pp. 2628-2634, 2017.

[15] J. Teizer, "Right-time vs real-time pro-active construction safety and health system architecture," Constr. Innov., vol. 16, no. 3, pp. 253-280, 2016.

[16] S. Wibawa, A. A. K. O. Sudana, and P. W. Buana, "Sistem Komunikasi Modul Sensor Jamak Berbasiskan Mikrokontroler Menggunakan Serial Rs-485 Mode Multi Processor Communication (Mpc)," Lontar Komput. J. Ilm. Teknol. Inf., vol. 7, no. 2, p. 122, Aug. 2016.

[17] S. J. Ray and J. Teizer, "Real-time construction worker posture analysis for ergonomics training," Adv. Eng. Informatics, vol. 26, no. 2, pp. 439-455, 2012.

[18] S. Hadiyoso and S. Aulia, "Multipoint to Point EKG Monitoring Berbasis ZigBee," Semin. Nas. Apl. Teknol. Inf. Yogyakarta, vol. 2135, pp. 1907-5022, 2014. 